\title{
Secondary maxima in ozone profiles
}

\author{
R. Lemoine \\ Royal Meteorological Institute of Belgium, 3, Avenue Circulaire, 1180 Brussels, Belgium
}

Received: 9 January 2004 - Published in Atmos. Chem. Phys. Discuss.: 23 March 2004

Revised: 28 June 2004 - Accepted: 30 June 2004 - Published: 8 July 2004

\begin{abstract}
Ozone profiles from balloon soundings as well as SAGE II ozone profiles were used to detect anomalous large ozone concentrations of ozone in the lower stratosphere. These secondary ozone maxima are found to be the result of differential advection of ozone-poor and ozone-rich air associated with Rossby wave breaking events. The frequency and intensity of secondary ozone maxima and their geographical distribution is presented. The occurrence and amplitude of ozone secondary maxima is connected to ozone variability and trend at Uccle and account for a large part of the total ozone and lower stratospheric ozone variability.
\end{abstract}

\section{Introduction}

Laminated ozone structures in the lower stratosphere have long been observed in ozone vertical profiles. Laminae observed in ozone vertical profiles from ozonesondes, are local extrema of the ozone concentration, situated in the lowermost part of the stratosphere. A lamina can be a local maximum or minimum of the concentration with a limited vertical extent of typically a few hundreds of meters. In some circumstances several laminae can be observed in one profile. In this case, layers of ozone-poor and ozone-rich air alternate. A secondary ozone maximum is the extreme case of a lamina where the maximum in the lower stratosphere is the same order of magnitude as the mid-stratospheric ozone concentration maximum. The associated minimum is well pronounced with concentrations well below the average.

Laminae in ozone profiles are very common at mid latitudes (Appenzeller and Holton, 1997) and have been the subject of many studies (Mlch and Lavstovivcka (1996) and references therein). Some studies consider laminae and secondary maxima in ozone vertical profiles separately while

Correspondence to: R. Lemoine

(rene.lemoine@meteo.be) others do not. The border line between laminae and secondary maxima can only be chosen arbitrarily, as all amplitudes and depths of ozone rich and poor layers exist between the finest lamina to the large secondary maximum.

Different approaches seem to coexist in the literature. The first, introduced by Dobson (1973) and supported by Varotsos et al. (1994) suggests that laminae are created through stratosphere-troposphere exchange near the subtropical jet stream.

The second view (Reid and Vaughan, 1991) presents differential advection of air from different locations as the likely origin for laminae. As this process is most active at high latitudes in winter and spring, Reid and Vaughan (1991) rule out the suggestion made by Dobson (1973) that laminae originate near the subtropical jet stream. Instead, the authors suggested that folds beneath the polar night jet might form laminae near the edge of the polar vortex. Although the possibility remains that a small number of laminae may be generated by stratosphere-troposphere exchange, Reid and Vaughan (1991) suggested that laminae may represent evidence of a process that can cause exchange of air in and out of the polar vortex.

Reid and Vaughan (1991) and Reid and Vaughan (1993) define ozone laminae as features between $200 \mathrm{~m}$ and $2.5 \mathrm{~km}$ in vertical extent which form a distinct layer of magnitude greater than $20 \mathrm{~m} \mathrm{~Pa}$. They found that laminae are most commonly found between 12 and $18 \mathrm{~km}$ at high latitudes in winter and spring. The abundance and amplitude of laminae increase with increasing latitude and the thickness decreases with increasing latitude. For the origin of laminae, they suggested that a mechanism operates at the lower edge of the polar vortex (where ozone mixing ratio increases sharply on isentropic surfaces) which transports ozone to middle latitude in the form of laminae, particularly during spring when the polar vortex dissipates. Possible candidates for this mechanism are inertia-gravity waves associated with the subtropical jet stream as proposed by Danielsen et al. (1991) or 


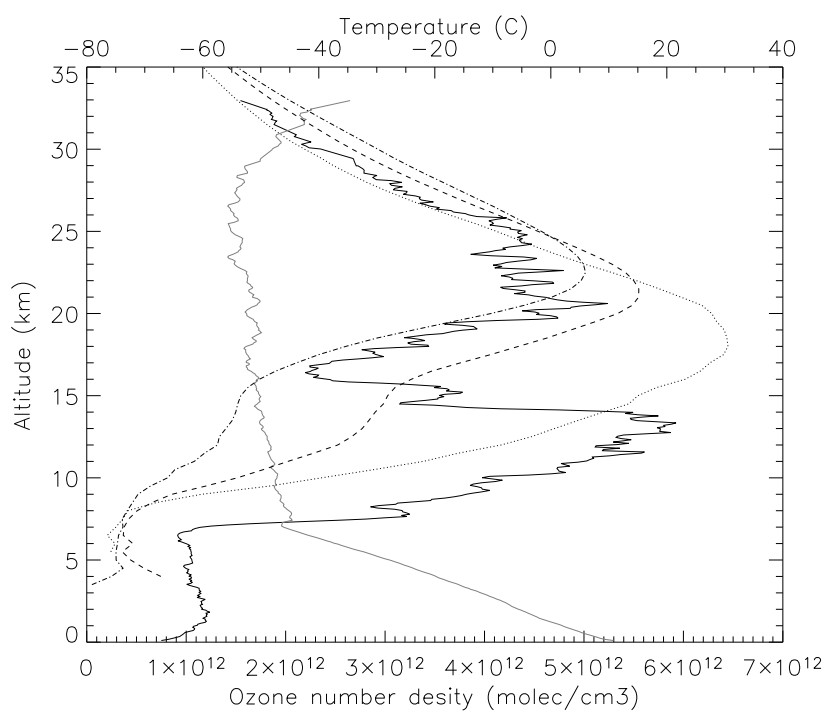

Fig. 1. Example of ozone secondary maxima observed in an ozone sounding on April 19, 2002 at Uccle. For comparison, SAGE II mean ozone profiles are shown for $30-40^{\circ} \mathrm{N}$ (dot-dashed curve), 40$50^{\circ} \mathrm{N}$ (dashed curve) and $60-70^{\circ} \mathrm{N}$ (dotted curve). The grey curve is the air temperature.

distortions of the polar vortex boundary by synoptic scale motions as proposed by Tuck et al. (1992).

Reid et al. (1994), using the EASOE ozonesonde archive, analyzed the occurrence of laminae in the course of the 1992 winter confirming the findings of Reid and Vaughan (1991) and Reid and Vaughan (1993). Laminae are most abundant near the edge of the polar vortex and are generally absent above $430 \mathrm{~K}$ inside the vortex. Observation of inertia-gravity waves in the lower stratosphere appears to suggest that such waves are not of sufficiently large amplitude to cause the kind of laminae that are observed.

Yet another approach to this phenomena is to use Lagrangian techniques to study laminated features in the ozone field. Plumb et al. (1994) and Waugh et al. (1994) used Lagrangian techniques to study the behavior of trace constituents in the boundary of the lower stratospheric vortex. Plumb et al. (1994) showed that vortex intrusions also occur during strong ridging events, during which the vortex is disrupted by one or several large-scale ridges. Such intrusions can lead to the formation of elongated thin filaments of midlatitude air inside the vortex.

Appenzeller and Holton (1997) determined regions in the middle atmosphere where the abundance of ozone laminae or laminae in a tracer distributed as potential vorticity (PV) is expected to be high. They estimated that laminae generation is expected to be most efficient where vertical wind shears coexist with tracer horizontal gradients.

In contrast with most of the above mentioned articles, this paper concentrates on laminae of larger vertical extent, often referred to as secondary ozone maxima. This paper is organised as follows. Sect. 2 presents the data used in this study. Sect. 3 gives the definition of a secondary ozone maximum and two examples are given in Sect. 4. The relation between the occurrence of ozone secondary maxima and the atmospheric circulation is developed in Sect. 5. Sections 6 and 7 present an in-depth analysis of ozone secondary maxima observed in ozone soundings at Uccle (Belgium) and in SAGE II ozone profiles. Sect. 8 describes the possible link between ozone trends and the occurrence of ozone secondary maxima.

\section{Dataset description}

Ozone soundings have been performed at Uccle, Belgium, since 1969 three times a week with two main interruptions in 1985 and 1986. Brewer-Mast ozone sensors were used from the beginning until March 1997 when it was decided to use model Z ECC ozone sensors. The vertical resolution of an ozone sounding is better than a few 100 meters. Given the high vertical resolution, ozonesondes are the most suitable instrument to study laminated structures in the lower stratosphere. A complete comparison between Uccle ozone profiles and SAGE II ozone profiles was performed by Lemoine and De Backer (2001).

The Stratospheric Aerosol and Gas Experiment II (SAGE II) is a seven-channel sun spectrophotometer launched in October 1984 aboard the NOAA ERBS satellite. SAGE uses the solar occultation technique that measures the attenuation of the solar radiation by the Earth's atmosphere at the limb due to scattering and absorption by different atmospheric species, primarily at $600 \mathrm{~nm}$ (Mc Cormick, 1987). During each spacecraft sunrise and sunset SAGE II provides water vapour, ozone, nitrogen dioxide and aerosol extinction profiles. The resolution of the instrument is not homogeneous, with a horizontal extent of the measurement of $200 \mathrm{~km}$ along the line of sight and $2.5 \mathrm{~km}$ in the perpendicular direction. The vertical resolution is set to $0.5 \mathrm{~km}$ in data version 6.0 and profiles extend from the tropopause up to $60 \mathrm{~km}$ altitude.

We used geopotential height, potential vorticity maps and wind fields to analyse the synoptic weather situation for a number of case studies. These data were provided by the European Center for Medium-range Weather Forecast.

\section{Definition of an ozone secondary maximum}

In this study, we only consider ozone secondary maxima. We define an ozone secondary maximum as a layer of ozonerich air where the ozone partial pressure is at least $75 \%$ of the ozone pertial pressure at the main maximum and that is separated from the main maximum by a layer of ozone-poor air where the ozone partial pressure is at most $75 \%$ that of the secondary maximum. There are no upper or lower limits on the thickness of the ozone-poor and ozone-rich layers. 

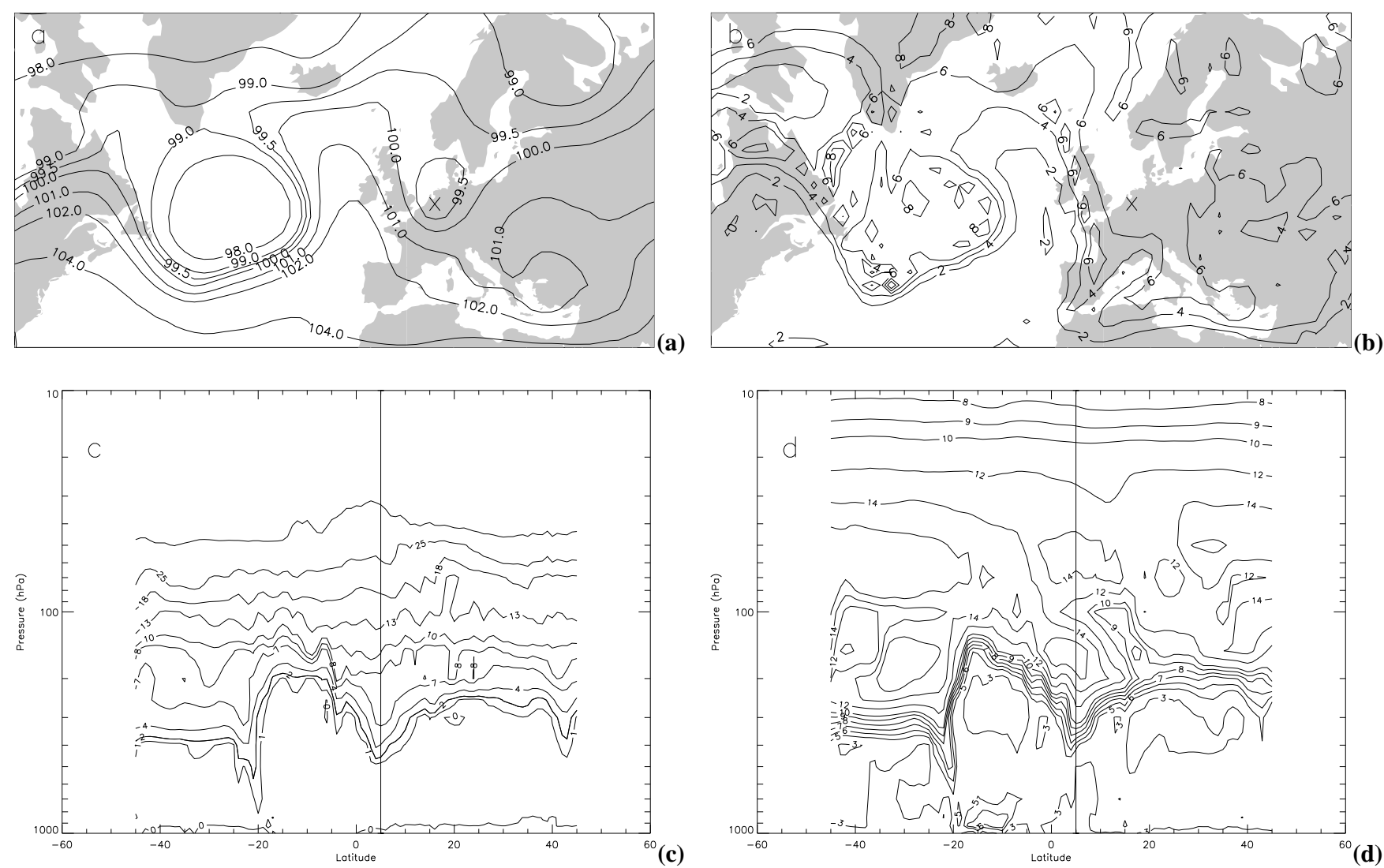

Fig. 2. Synoptic situation on 20020419 extracted from ECMWF analysis. (a) $250 \mathrm{hPa}$ geopotential height $\left(10^{5} \mathrm{~m}^{2} / \mathrm{s}^{2}\right)$ and (b) $330 \mathrm{~K} \mathrm{potential}$ vorticity (PVU). The location of Uccle is marked with an $\mathrm{x}$. Cross-sections between -45 and $+45^{\circ}$ longitude at $50^{\circ} \mathrm{N}$. (c) potential vorticity (PVU) and (d) ozone partial pressure $(\mathrm{mPa})$. The vertical line in the bottom figures correspond to the Uccle longitude.

In order to be used in this survey, the ozone sounding must have reached the $20 \mathrm{hPa}$ level to ensure that the main ozone maximum was measured. The same criteria are applied to SAGE II profiles to detect secondary maxima. The lower vertical resolution of the SAGE profiles should have little or no influence on the detection of secondary maxima: given the usually observed thickness of the ozone-rich and ozone-poor layers (see Sect. 4), secondary ozone maxima are resolved by SAGE.

\section{Example}

On April 19, 2002 a particularly remarkable secondary ozone maximum was observed in an ozone sounding at Uccle. The geopotential height and PV charts (Fig. 2a and b) show a ridge associated with low-PV air on the Eastern Atlantic and a trough region associated with high-PV air above Western Europe. This trough is limited to the very lower stratosphere and is not visible in geopotential height and PV maps above $100 \mathrm{hPa}$.

Longitude-height cross sections of the PV and ozone fields at $50^{\circ} \mathrm{N}$ shown in Fig. $2 \mathrm{c}$ and $\mathrm{d}$ are extremely similar to
Fig. 10 in O'Connor et al. (1999). The intrusion between $20^{\circ} \mathrm{W}$ and $0^{\circ} \mathrm{W}$ is clearly visible in both the PV and ozone fields and extends up to $350 \mathrm{~K}$. On the other and, the secondary ozone maximum above Uccle $\left(5^{\circ} \mathrm{E}\right)$ is well resolved in the ozone field as ozone-rich air underneath ozone poor air but it is not present in the PV field.

Ten days isentropic backward trajectories were computed with the FLEXTRA model and ECMWF wind fields analyses. Clusters of trajectories were used to check the reliability of the result. Isentropic trajectory clusters ending at $200 \mathrm{hPa}$ and $90 \mathrm{hPa}$ above Uccle on 19 April 2002 are presented in Fig. 3a and b. Trajectories ending at $200 \mathrm{hPa}$ correspond to the secondary ozone maximum and trajectories ending at $90 \mathrm{hPa}$ correspond to the associated ozone minimum.

The trajectories ending at $90 \mathrm{hPa}$ have their origin near $\left(30^{\circ} \mathrm{N}, 110^{\circ} \mathrm{W}\right)$ around $70 \mathrm{hPa}$, in the lower stratosphere. The ozone partial pressure measured by the ozonesonde agrees with ozone values from the ECMWF assimilated ozone data. Higher up in the stratosphere, additional trajectory calculations (not shown) showed that the atmosphere up to $50 \mathrm{hPa}$ is made of air that was advected from close to $30^{\circ} \mathrm{N}$. 

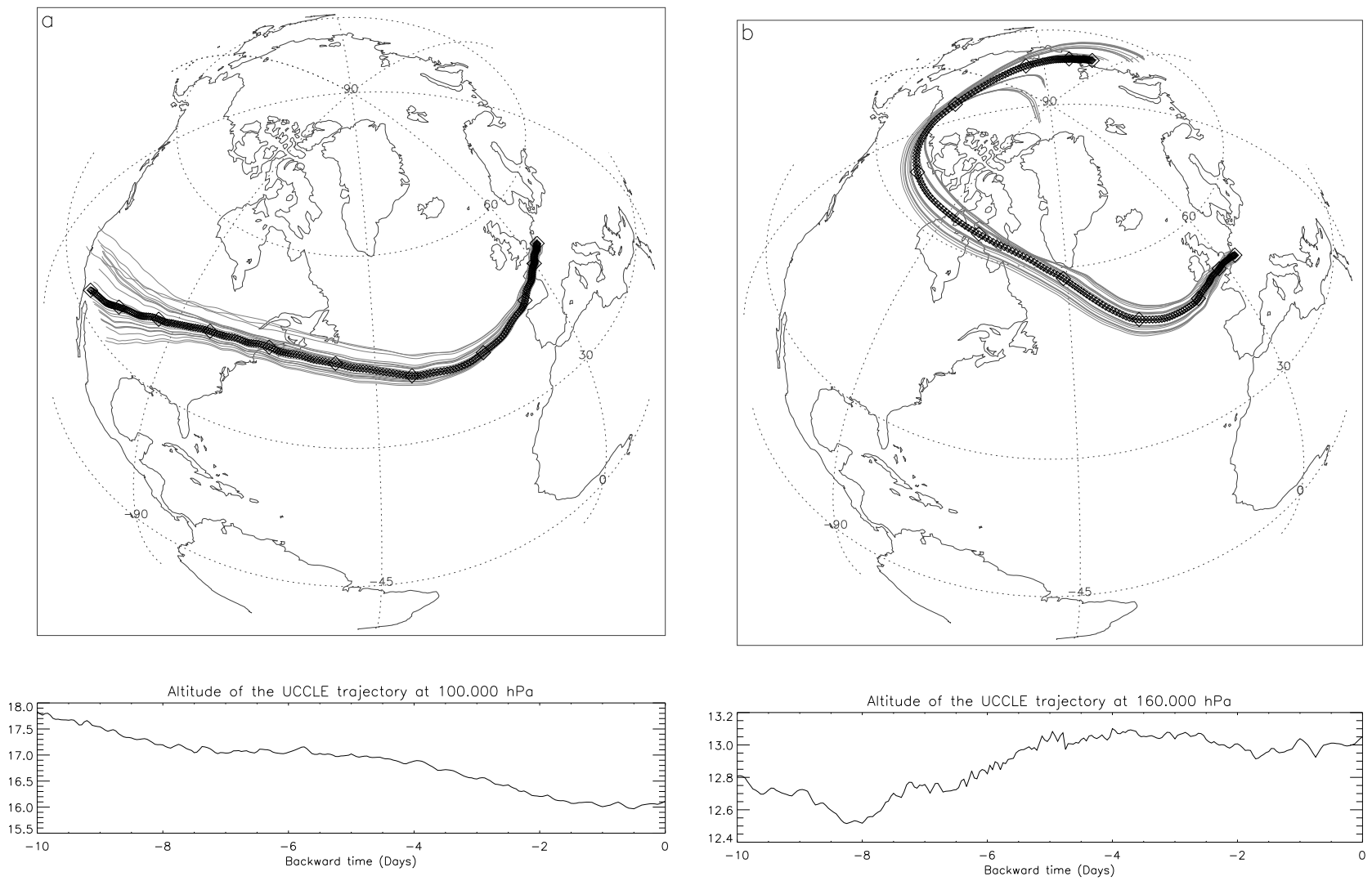

Fig. 3. 10 days isentropic back trajectory clusters and altitude of the trajectory ending above Uccle. Clusters are made of 25 trajectories with end points on a 2 by 2 degree grid centered on Uccle and spaced by 0.5 degree. (a) trajectories ending at 100hPa on 20020419 12:00 UT. (b) trajectories ending at $160 \mathrm{hPa}$ on 20020419 12:00 UT. The pressure levels correspond to the pressure at which the secondary ozone maximum and minimum were observed in the sounding.

The trajectories corresponding to the secondary maximum have their origin north of the arctic circle and well inside the polar vortex, according to PV maps. The ozone rich air mass above Uccle on 19 April 2002 is thus associated with a low geopotential trough and a equatorward intrusion of high ozone concentration and high PV air from the base of the polar vortex. The ozone-poor air at $100 \mathrm{hPa}$ is associated with low latitude stratospheric air that extends up to at least $30 \mathrm{hPa}$. The presence of the poleward and equatorward intrusion create an strong disruption of the base of polar vortex edge which is turned in a North-South direction. The perturbation is not present at higher altitudes where the wave has not (yet) propagated. The vertical wind shear induced is well captured in Fig. 3 where the $200 \mathrm{hPa}$ trajectory turns at a right angle one day before passing over Uccle while the $100 \mathrm{hPa}$ trajectory does not. It is important to note that the wind shear is not obvious in the sounding data in this case. More generally, there is no systematic association of secondary maxima with an important wind shear in ozone soundings. The reason is that secondary ozone maxima are most pronounced downstream of the frontal region where the wind shear is no more present.

\section{Secondary ozone maxima and Rossby wave breaking}

In the northern hemisphere, planetary-scale Rossby waves constitute a primary source of dynamical variability. Given the long chemical lifetime of ozone in the lower stratosphere, reversible transport associated with Rossby waves accounts for the largest part of ozone variability in winter and spring. In addition to reversible transport, irreversible transport occurs during Rossby wave breaking events. Such events are associated with troposphere-stratosphere exchange and tropopause folds. Wave breaking events can be classified as either "equatorward" or "poleward". On potential vorticity maps, equatorward breaking events, tongues of high potential vorticity $(\mathrm{PV})$ air extend equatorward and in poleward events, tongues of low PV air extend poleward.

Peters and Waugh (1996) studied a number of Rossywave-breaking events which resulted in the poleward advection of upper tropospheric air from the subtropics during winter. They identified two types of poleward breaking: type $1(\mathrm{P} 1)$ in which the intruded tropospheric air tilts upstream, thins and is advected cyclonically and type 2 (P2) in which the air tilts downstream, broadens and wraps up 
Table 1. Altitudes and latitudes of the back trajectories calculated for the ozone-rich (MAX) and ozone-poor (MIN) air-masses observed with a secondary ozone maximum. All trajectories end above Uccle $\left(50.8^{\circ} \mathrm{N}, 4.35^{\circ} \mathrm{E}\right.$.)

\begin{tabular}{llrcc}
\hline Date & Airmass & $\begin{array}{r}\text { Origin of the } \\
\text { airmass }\end{array}$ & $\begin{array}{c}\text { Altitude } \\
\text { at }-10 \text { days }(\mathrm{km})\end{array}$ & $\begin{array}{c}\text { Altitude } \\
\text { above Uccle }(\mathrm{km})\end{array}$ \\
\hline \multirow{2}{2}{00000407} & MAX & $61.3^{\circ} \mathrm{N}$ at -6 days & 11.5 & 11.8 \\
& MIN & $36.7^{\circ} \mathrm{N}$ at -9.5 days & 13.8 & 13.5 \\
20000412 & MAX & $85.7^{\circ} \mathrm{N}$ at -6.6 days & 12.3 & 11.3 \\
& MIN & $29.7^{\circ} \mathrm{N}$ at -10 days & 18.3 & 16.6 \\
20010226 & MAX & $77.3^{\circ} \mathrm{N}$ at -9.5 days & 13.8 & 14.6 \\
& MIN & $39.6^{\circ} \mathrm{N}$ at -8.1 days & 16.7 & 15.7 \\
20010330 & MAX & $71^{\circ} \mathrm{N}$ at -10 days & 12.3 & 12.7 \\
& MIN & $34.5^{\circ} \mathrm{N}$ at -10 days & 15.9 & 15.2 \\
20020419 & MAX & $78.3^{\circ} \mathrm{N}$ at -7.7 days & 12.7 & 13.0 \\
& MIN & $34^{\circ} \mathrm{N}$ at -10 days & 17.7 & 16.0 \\
\hline
\end{tabular}

anticyclonically. P1 breakings are expected on the cyclonic side of jets and P2 on the anticyclonic side. The authors observed that Rossby waves propagate along the jet and break in the region of weak zonal winds. They also noted that the wave breaking events occurred in two preferred locations that are consistent with the preferred regions of blocking: Atlantic Ocean/Europe and Pacific Ocean/North America.

P2-type wave-breaking events can lead to the advection of air from close to the subtropical jet stream into the midlatitude lower stratosphere. This mechanism can lead to the formation of ozone secondary maxima, as was shown by O'Connor et al. (1999). In the two case-studies presented in that paper, breaking events led to irreversible transport of air from the subtropics to the mid-latitudes, up to $365 \mathrm{~K}$ potential temperature.

P1 and P2-type wave breaking events seem to be the most common origin of ozone secondary maxima observed at Uccle. We used PV maps on $315 \mathrm{~K}$ and $330 \mathrm{~K}$ potential temperature levels from the ECMWF assimilation system to analyse the synoptic situation on days when a secondary ozone maximum was observed at Uccle. Out of 17 well-resolved secondary ozone maxima events observed between January and April in 2001 and 2002, 7 were associated with P1 wave breaking events, 7 with P2 events and 3 could not be easily classified or were associated with equatorward wave breaking events. In all cases where a P1 or P2 event was identified, Uccle was situated on the Eastern or Northern edge of the poleward intrusion, but outside it and under a trough of low geopotential height and high PV air at $315 \mathrm{~K}$ that preceded the intrusion. The lower stratospheric ozone-rich air layer was associated with high PV values above Uccle, and could be best observed at 315 or $330 \mathrm{~K}$ potential temperature levels. On the other hand, PV fields at the height of the ozone-poor air layer above Uccle (about $100 \mathrm{hPa}$ or $430 \mathrm{~K}$ ) were generally completely different with no signature of the equatorward wave structure.
Five detailed cases studies of ozone secondary maxima events have been performed. These events took place in 2000, 2001 and 2002. In addition to the above mentioned synoptic situation analysis, we used ECMWF wind field analyses to compute 10 days backward isentropic trajectories with the FLEXTRA trajectory model (Stohl, 2001, and references therein). Clusters of trajectories were used to check the reliability of the result. Trajectories were started at the height of the secondary maxima and associated minima. An example is given in Fig. 3 .

The results obtained are summarised Table 1 . In all cases, the low ozone content air masses that make the ozone minima were advected from $30-40^{\circ} \mathrm{N}$ latitude across the Atlantic up to western Europe. The overall vertical displacement of these air parcels is descending with an initial altitude between $14 \mathrm{~km}$ and $18.5 \mathrm{~km}$ at -10 days. The amplitude of the vertical displacement along the trajectory can be as large as $2.5 \mathrm{~km}$ in several cases. It is important to note that Rossby wave breaking events have been identified as the likely origin of stratosphere-troposphere exchanges (Peters and Waugh, 1996) and play a role in the appearance of mini ozone holes (Hood et al., 1999). However, the results obtained here rule out the possibility that the ozone-poor air layer observed with ozone secondary maxima is air of tropospheric origin (Dobson hypothesis). The ozone-poor air mass has its origin the the lower stratosphere and is advected downward along the isentropes.

The ozone-rich air masses are of polar origin and are associated with high (vortex-like) PV values at the same altitude in the ECMWF PV maps. The corresponding back trajectories pass generally North of $70^{\circ} \mathrm{N}$ latitude within 10 days before the secondary maximum was observed at Uccle. There is no pronounced systematic vertical positive or negative displacement, which is always smaller than $1.5 \mathrm{~km}$. 

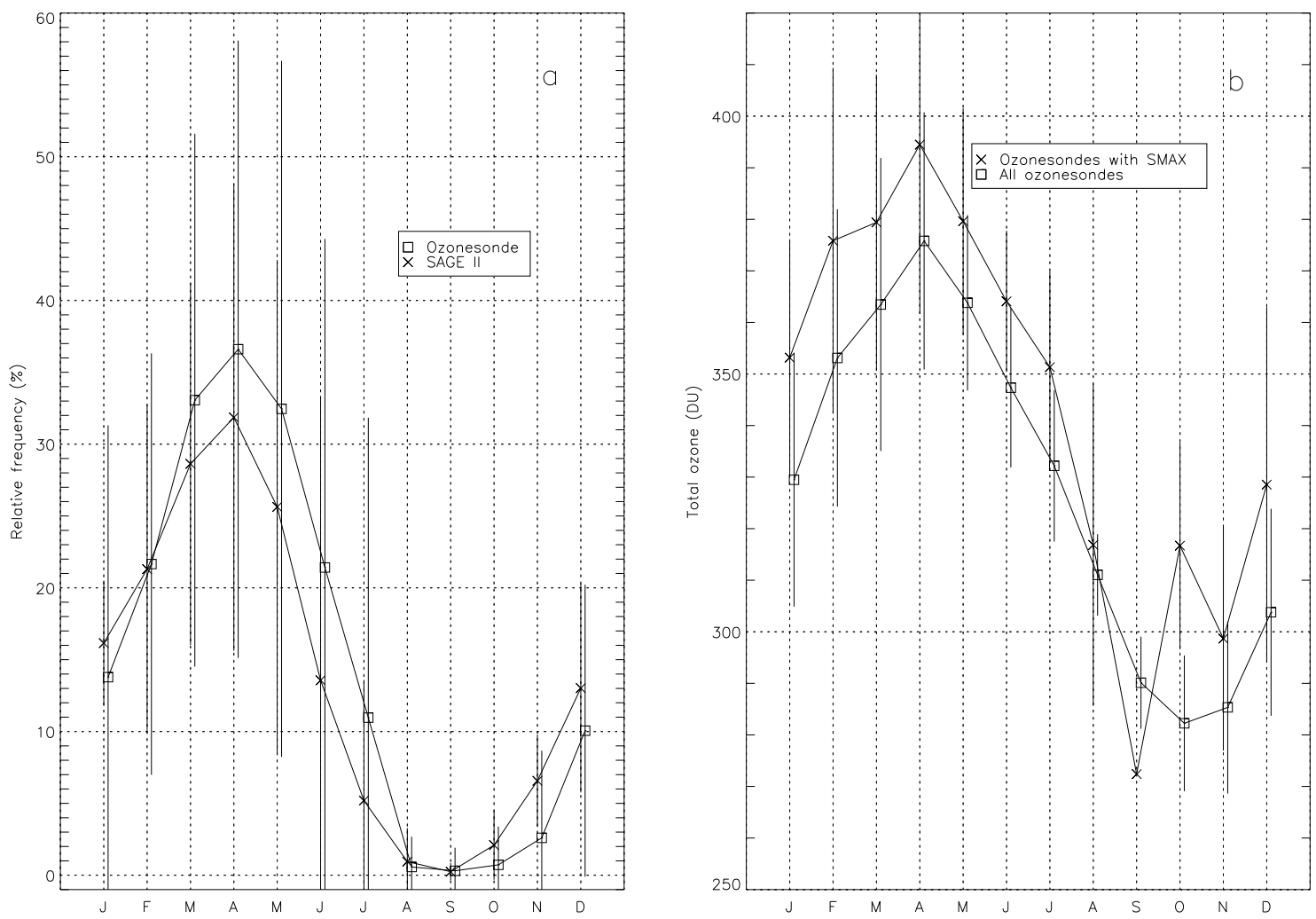

Fig. 4. (a) Secondary maxima monthly mean relative frequencies in Uccle ozone soundings and SAGE II ozone profiles in the latitude band 45-55N. (b) Total ozone column above Uccle for days with a secondary maximum and for all days with a sounding.

\section{Frequency and seasonal cycle}

Uccle ozone soundings were systematically scanned for secondary maxima and we calculated the relative frequency of occurrence (RF) of secondary ozone maxima, that is, the fraction of ozone soundings at Uccle that showed a secondary ozone maximum. Figure 4a shows the monthly mean RF averaged over the period 1969-2001. Secondary maxima RF are higher during winter with a maximum in March-May, decrease sharply in June and July and fall to almost zero from August to November. This figure, in agreement with the findings of Mlch and Lavstovivcka (1996), is consistent with the scenario where laminae and secondary maxima appear in conjunction with intense planetary wave activity and large disruptions of the polar vortex. The maximum RF occurs in March-April (Fig. 4a), which is the time of the year when the final breakdown of the northern polar vortex generally occurs.

As the occurrence of secondary maxima is closely related to the state and position of the polar vortex, the occurrence of secondary maxima should also show some correlation with the total ozone column. It is clear from Fig. $4 \mathrm{~b}$ that secondary maxima RF are highly correlated with the total ozone seasonal cycle at Uccle. Figure $4 \mathrm{~b}$ also shows that the total ozone column is, in the average, higher than the clima- tology by $20 \mathrm{DU}$ when a secondary maximum is observed. This can be explained by the fact that the tropopause is generally lower in or near the polar vortex than outside of it. And indeed, the observed average tropopause altitude for secondary ozone maxima events (Fig. 5a) is lower than the average tropopause altitude for all soundings by 1 to $2 \mathrm{~km}$. It is interesting to note that there is almost no seasonal cycle in the tropopause height when a secondary ozone maximum is observed while there is one in the mean tropopause height. Total ozone columns are higher even if the ozone minimum represents a loss compared to an undisturbed typical vortex ozone profile. The integrated ozone value between the tropopause and the minimum (Fig. 5d) varies between 40 and $80 \mathrm{DU}$ with large case-to-case variations.

The criterion to select secondary maxima uses relative differences between the secondary maximum and main maximum and between the minimum and secondary maximum. Hence, there is no truncation at some threshold level and it makes sense to look at the absolute ozone concentration of the secondary maxima and its associated minima. Values are shown in Fig. 5b. The ozone partial pressure at the secondary maximum has a well pronounced seasonal cycle while the partial pressure of the minimum shows little variation over the year. The cycle of the secondary maximum partial pressure corresponds to the seasonal cycle of the lower 

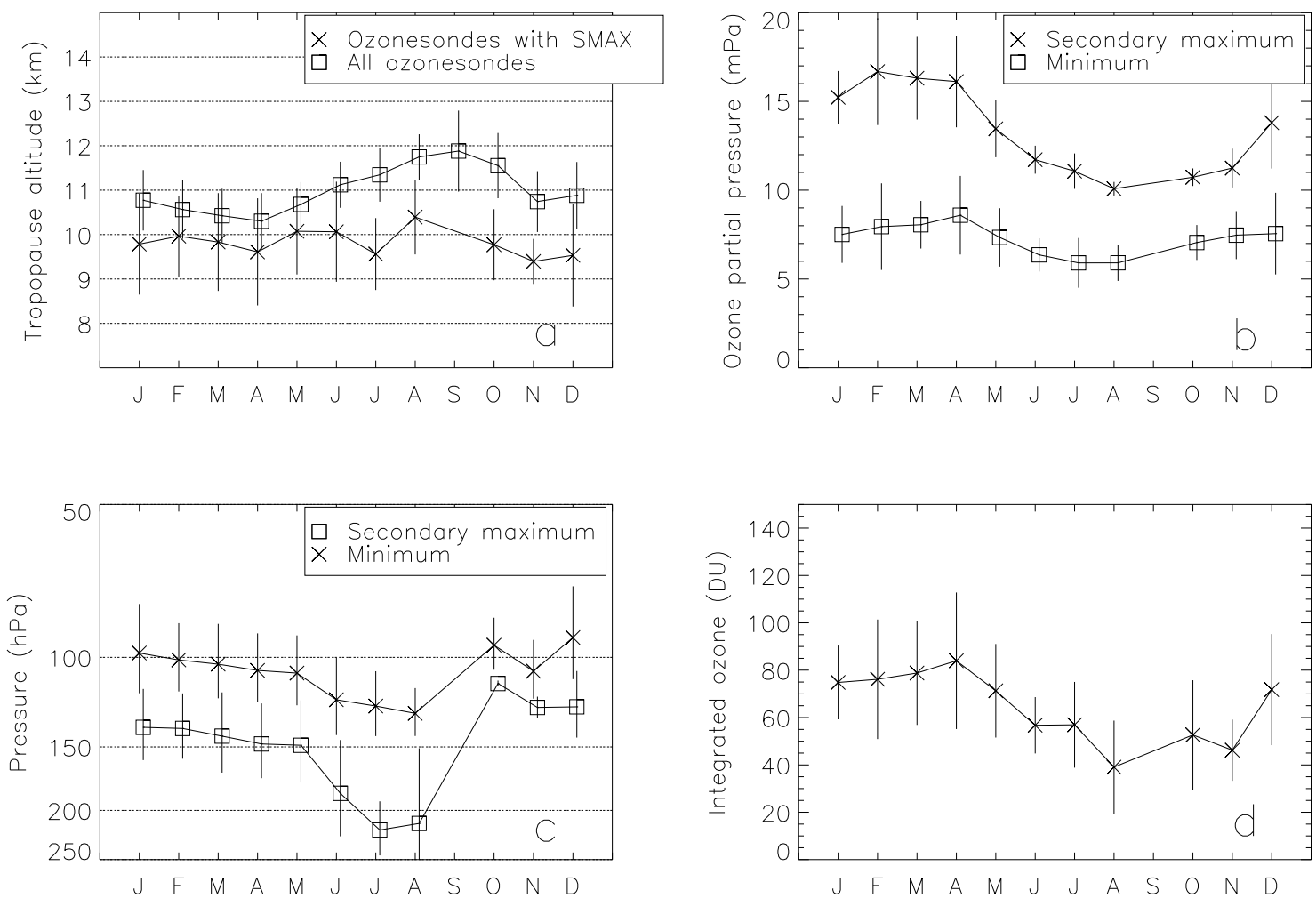

Fig. 5. (a) Monthly mean tropopause altitude for soundings with a secondary maximum and for all soundings. (b) Monthly mean ozone partial pressure of the secondary maxima and of the associated minima. (c) Monthly mean air pressure at the level of secondary maxima and associated minima. (d) Integrated ozone between the tropopause and the minimum concentration height. This graph gives the mean total ozone content of the secondary maximum. Error bars are one standard deviation on the mean. The period covered is 1969-2001.

stratospheric polar ozone, as ozone accumulates at the base of the polar vortex during winter, see Sect. 5. The partial pressure of the minimum is representative of lower stratospheric low latitude air which undergoes little seasonal variation. It is also clear from this figure that secondary maxima are more pronounced (larger ozone concentration difference between the minimum and the maximum) between December and April than the rest of the year.

Ozone secondary maxima at Uccle occur typically around 140 to $160 \mathrm{hPa}$ in winter and spring and below the $170 \mathrm{hPa}$ level in summer (see Fig. 5c). This seasonal cycle is less pronounced in the corresponding curve of the associated minima. The minima typically occur around the 90 to $100 \mathrm{hPa}$ level in winter and spring, with somewhat lower altitudes in summer. In this case, the larger pressure difference between the minimum and the maximum occurs in summer and is smallest in October and November.

\section{Zonal distribution}

Using SAGE II ozone profiles, the zonal mean RF as well as the longitude/latitude distribution of secondary ozone maxima can be investigated in much more detail than in previous studies. Of particular interest is the longitude/latitude distri- bution shown in Fig. 6. The most striking features are the strong differences between the two hemispheres and the latitude gradient of the RF, with no ozone secondary maxima observed in the tropics and highest RF at high latitudes.

Appenzeller and Holton (1997) presented a climatology of lamination based on theoretical work and model calculation. They based their calculation on the size of the thermal wind shear derived from satellite temperature observations, and the size of ozone/tracer horizontal gradients. They showed that the production rate of ozone laminae has a dip between 30 and $10 \mathrm{hPa}$, likely because of the reversal of the ozone latitudinal gradient, and it then maximizes near $5 \mathrm{hPa}$. The zonal and seasonal distribution of secondary maxima observed by SAGE roughly agrees with the results by Appenzeller and Holton (1997) and the seasonal cycle of lamination in the lower stratosphere is also well described. However, substantial differences appear, especially in the southern hemisphere where the observations by SAGE exhibit a strong asymmetry between the southern and northern hemisphere which is not reproduced by Appenzeller and Holton (1997). Also, secondary maxima RF steadily increase with increasing northern latitude except above western Europa and do not present a mid-latitude maximum found by (Appenzeller and Holton, 1997). 

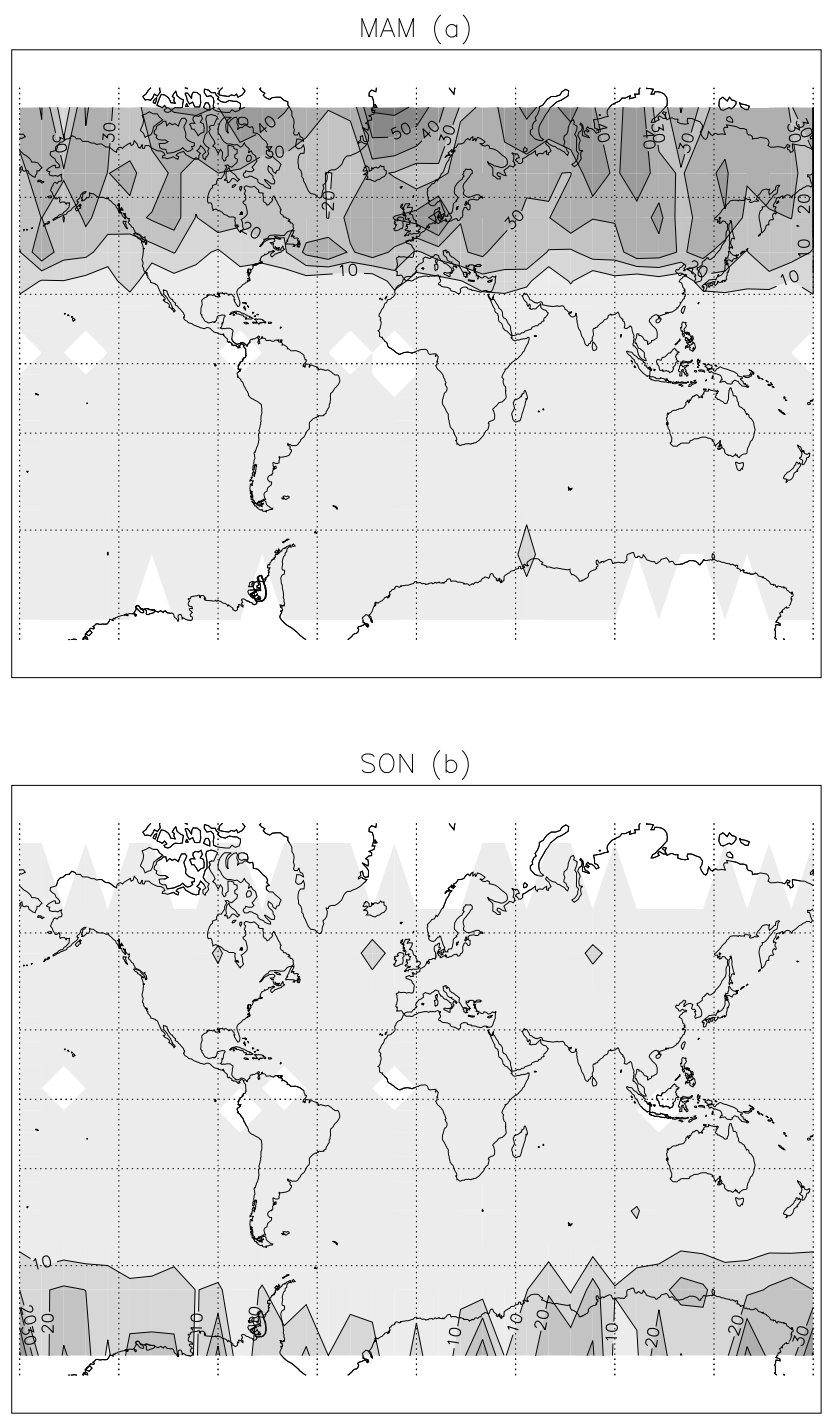

Fig. 6. Mean distributions of the percentage occurrence of ozone secondary maxima relative frequencies computed from SAGE II ozone profiles for (a) March to May and (b) September to November. Areas where no data are available are white.

The origin of theses difference might be due to the different treatment of laminae, as thin or weak lamina are excluded from the present study.

Ozone secondary maxima are not evenly distributes in longitude, as expected from the observed association between secondary maxima and Rossby wave activity (Sect. 5). In the Northern hemisphere, secondary maxima appear preferentially in regions and at times where the atmospheric circulation is active, and planetary wave activity perturbs the polar vortex. Furthermore, the maximum RF in the north-eastern Atlantic, North Sea and Denmark seems to correspond to the eastern side of the northern Atlantic storm track (e.g. James, 1994).
The situation in the southern hemisphere is more complex as SAGE profiles measured in the ozone hole show low ozone values in the mid stratosphere, much like a secondary maximum. It is therefore very difficult to separate profiles showing a real dynamical secondary maximum, from ozone hole-type profiles where low ozone values in the lower stratosphere are due to chemical depletion, at least at high latitudes. Nonetheless, it is clear that ozone secondary maxima occur much less frequently in the SH mid latitudes, (where no interference with the ozone hole is possible) than in the $\mathrm{NH}$ mid latitudes. The difference between the northern and southern hemisphere is likely due to the different circulation patterns in the mid latitudes, especially the much less frequent blocking systems in the southern hemisphere.

\section{Trends in atmospheric circulation and ozone varia- tion}

\subsection{Trends in secondary maxima}

Figure 7a shows the time series of the mean February-May secondary maxima RF observed in Uccle ozone soundings and SAGE II profiles between $45^{c} i r c \mathrm{~N}$ and $55^{\circ} \mathrm{N}$ latitude. Large year to year variations can be observed in both time series but with a reasonable correlation between Uccle and SAGE II even if SAGE II data are zonal mean values. There is no noticeable long term trend in the RF timeseries, in contrast with the results of Mlch and Lavstovivcka (1996) who found pronounced negative trends in laminae occurrence at two central Europe sounding stations. The reason might again be in the exclusive consideration of large laminae in this study. Smaller laminae (included in the work by Mlch and Lavstovivcka (1996)) are confined to regions close to the polar vortex boundary so that their detection is extremely sensitive to the position of the polar vortex boundary. A small northward displacement of the vortex boundary will have a much greater impact on small laminae occurrence than on secondary maxima occurrence.

Figure $7 \mathrm{~b}$ shows the mean February-May intensities of the ozone concentration of the secondary maxima and minima. Both show large year to year variations. A linear regression on the time series shows a significant negative trend for the secondary maximum intensity of $-4.5 \% \pm 2.2 \%$ per decade $(1 \sigma)$, similar to the $-5 \%$ per decade trend at $200 \mathrm{hPa}$ at Resolute $\left(75^{\circ} \mathrm{N}\right)$ for the period 1970-1996 (WMO, 1998).

Hood et al. (1999) and Steinbrecht et al. (2001) used one or several parameterizations of the atmospheric circulation in order to evaluate the contribution of the atmospheric circulation to decadal ozone trend in winter and spring month. In a similar exercise, following Fusco and Salby (1999) who showed that inter annual variation of total ozone operate coherently with variations of planetary wave activity, it could be tried to use the RF of observed secondary ozone maxima as a measure of the planetary wave activity at a given 

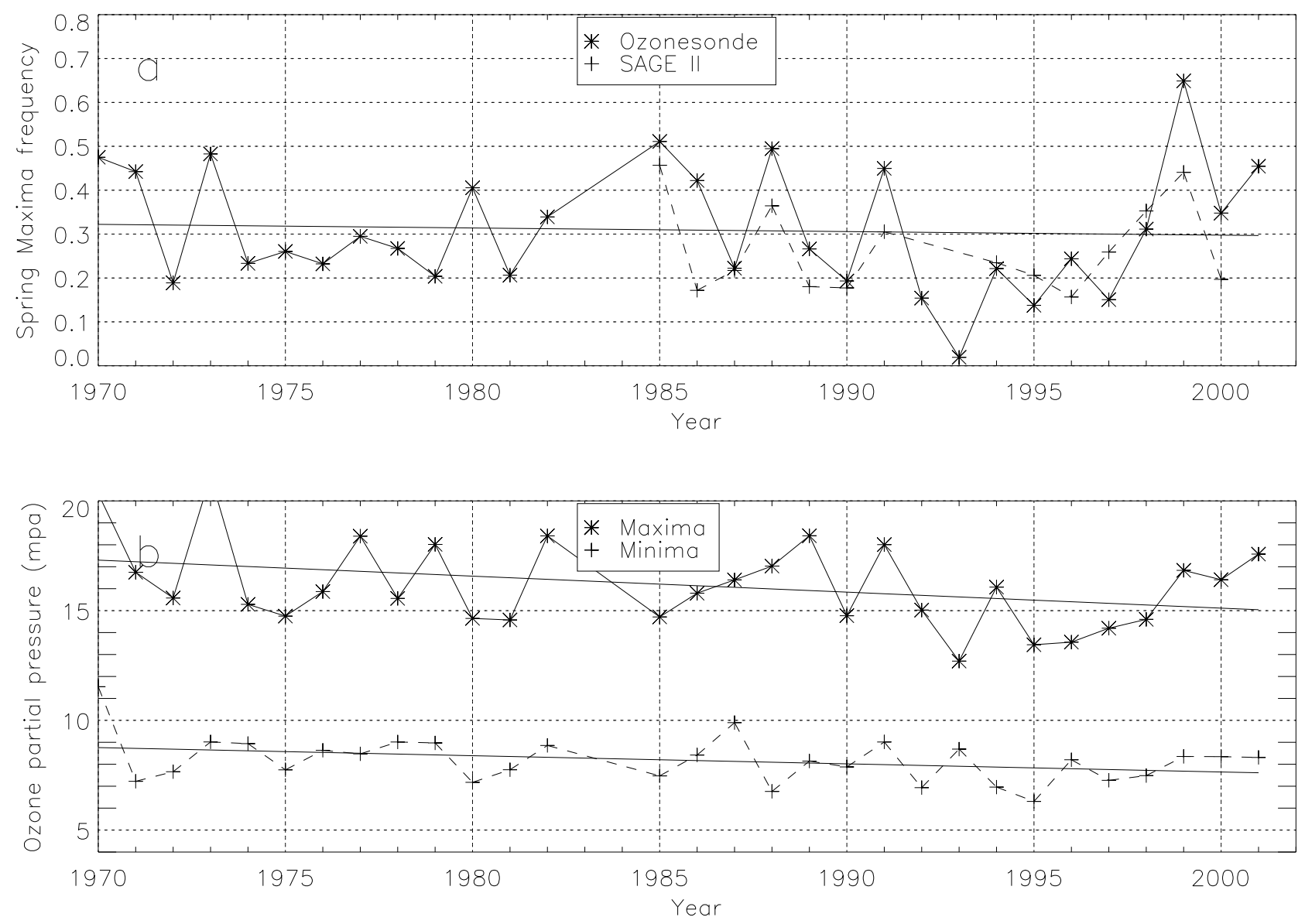

Fig. 7. (a)Mean secondary maxima relative frequency in spring, from ozonesonde and SAGE II data. (b) Mean ozone partial pressure of the ozone secondary maxima and minima, from ozonesonde data.

location. We tried to relate this RF to the fluctuation of the total ozone column at the same location. This implies that the rate of ozone secondary maxima at a given station is representative of the frequency of maxima on a global scale. Although the zonal distribution is inhomogeneous (see Fig. 6), the RF of secondary maxima observed at Uccle compare reasonably well with the zonal mean values calculated from by SAGE II (see Figs. 4 and 7a).

The second parameter that can also be used to describe the atmospheric ozone content variability is the intensity of the secondary maxima. This value can be taken as a measure of the lower polar vortex ozone concentration and can be expected to have an influence on the average lower stratospheric ozone content as well as total ozone content down to mid latitudes. This is supported by the fact that most of the day-to day ozone variability comes from ozone variations in the lower stratosphere. It is important to note that any long term trend in ozone concentration due to chemical ozone depletion in the lower polar vortex could influence the intensity of secondary maxima.

\subsection{Trends in ozone}

A simple multiple linear regression model was used to describe both the average total ozone content in spring above Uccle and the average ozone concentration in the lower stratosphere in spring above Uccle.

The ozone variability is described by

$$
\begin{aligned}
& \mathrm{O}_{3}(t)=C_{0} t+C_{1} S M A X_{F r e q}(t) \\
& +C_{2} S M A X_{\text {Intensity }}(t)+C_{3} S F(t)
\end{aligned}
$$

where $\mathrm{O}_{3}(t)$ is the ozone time series, $C_{0}$ is the fitted decadal trend, $S M A X_{F r e q}(t)$ is the ozone secondary maxima relative frequency, $S M A X_{\text {Intensity }}(t)$ is the ozone secondary maxima intensity time series, and $S F(t)$ is the solar flux variability.

This linear regression model was applied on the 30 years long time series of total ozone and lower stratospheric ozone concentration at Uccle. The total ozone timeseries is the mean total ozone column measured at Uccle by the Dobson instrument. All values are mean values for the month February to May for each year. 

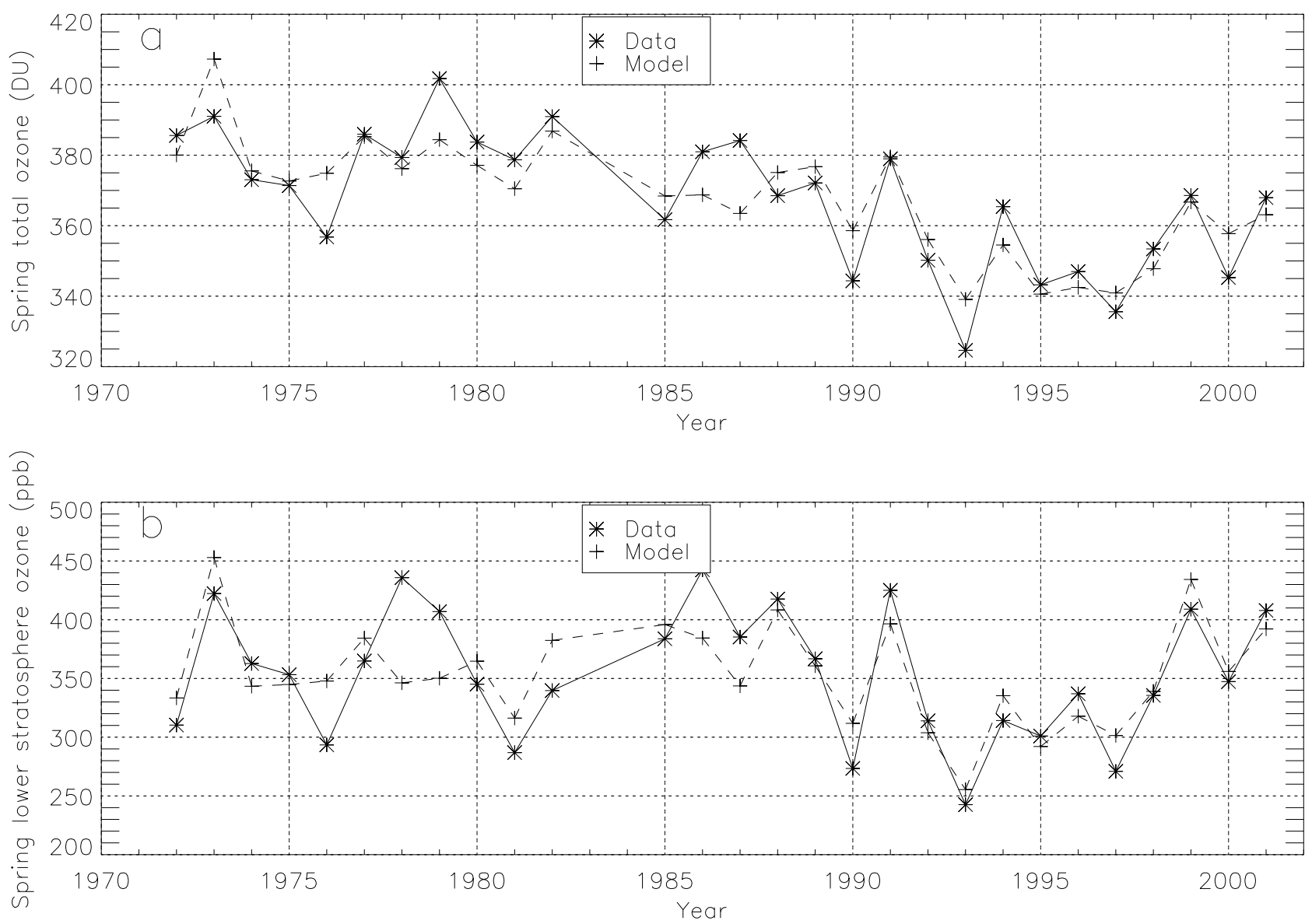

Fig. 8. (a) Mean spring Dobson total ozone at Uccle and results of the linear regression model. (b) Mean lower stratospheric spring ozone content at Uccle and result of the linear regression model.

The linear regression presented here includes a linear trend, the RF, and the intensity of ozone secondary maxima measured at Uccle and the solar flux variability. This model is not intended to provide a complete description of the contributions to ozone variations. However, this model that simulates a simple linear trend and the influence of two dynamical parameters is able to account for $73 \%$ of the average spring (February to April) total ozone variability. The correlation coefficient between the time series and the regression model is $R=0.86$. The same model is able to account for $63 \%(R=0.79)$ of the lower stratospheric ozone concentration variability. The lower stratospheric ozone is taken to be the average ozone concentration between 11 and $13 \mathrm{~km}$ altitude. The results are shown in Fig. 8.

Looking at the spring lower stratospheric ozone concentration first (Fig. 8b), we see that the model is able to reproduce a large part of the variability. The long term trend calculated with the model is $-1.68 \% \pm 2.38 \%$ per decade ( 1 sigma uncertainties). This value is not significant, even at the $68 \%$ confidence level. This figure can be compared to the value of $-2.44 \%$ per decade obtained with a simple linear regression.
This means that the ozone variability and the observed long term ozone trend in the lowermost stratosphere can be described with the dynamical index given by $S M A X_{\text {Freq }}$ and a measurement of the lower polar vortex ozone concentration given by $S M A X_{\text {Intensity. Since there is almost no long }}$ term trend in the RF time series (Fig. 7a), this means that the trend in the lower stratospheric ozone concentration at Uccle is explained by trend in the polar lower stratosphere ozone content, represented here by $S M A X_{\text {Intensity }}$.

The spring total ozone column variability (Fig. 8a), on the other hand, cannot be described by the parameterization alone as the remaining trend given by the regression model is is $-3.26 \% \pm 0.67 \%$ per decade and is $2 \sigma-$ significant. This trend can be explained by ozone depletion in the mid and upper stratosphere, at altitudes above those where ozone secondary maxima appear. Ozone depletion at mid-latitudes measured by ozonesondes shows significant negative trends that maximizes in the pressure range 200$50 \mathrm{hPa}$ (WMO, 2002), thus extending well above typical altitudes of the phenomena studied here. Therefore, the trends in the middle and upper-stratosphere are not accounted for 
by the parameterization used here. The remaining trend of $-3.26 \% \pm 0.67 \%$ is representative of the total ozone trend that is directly due to the effective reduction of ozone concentration in the middle atmosphere at mid latitudes.

\section{Conclusions}

Thirty years of ozone soundings at Uccle and 15 years of SAGE II ozone profile data were analyzed to look for strong lamination events in the lower stratosphere called ozone secondary maxima.

This study showed that:

- Ozone secondary maxima observed in ozone soundings at Uccle occur often in conjunction with Rossby wave breaking events, mostly poleward backward and forward wave breaking events.

- Ozone secondary maxima are most frequent in spring in both datasets and show a seasonal cycle that follows closely the total ozone seasonal cycle. Using SAGE II ozone profiles, the zonal distribution of secondary maxima can be observed. This zonal distribution is not homogeneous, with a correlation between the places of occurrence of ozone secondary maxima and atmospheric circulation patterns.

- Using trajectory calculations, we found that secondary ozone maxima are created through differential advection in the lower stratosphere of ozone-rich air that comes from Northern high latitudes underneath ozonepoor air advected from close to the tropics. For the 17 cases studied, troposphere to stratosphere exchange as suggested by Dobson (1973) was not found and did not create the secondary maxima there.

- Year-to year variation of the mean relative frequency of ozone secondary maxima as well as the variation of the mean intensity of the maxima can be used as an easily accessible measure of the atmospheric dynamical activity, or at least its component that has a direct influence on atmospheric ozone content variability. A multiple linear regression model using these two quantities can explain $73 \%$ of the mean February-April total ozone variability with a remaining trend of $-3.26 \%$ per decade. The same model applied on the lower stratospheric ozone content explains $63 \%$ of the variability with no significant remaining trend.

Acknowledgements. This work was supported by the EUMETSAT Ozone Satellite Application Facility program. SAGE II ozone data are made available on-line by the NASA Langley Research Center (NASA-LaRC) and the NASA Langley Radiation and Aerosols Branch. The FLEXTRA trajectory model is made available by A. Stohl, Technical University of Munich.

Edited by: M. Dameris

\section{References}

Appenzeller, C. and Holton, J. R.: Tracer lamination in the stratosphere: a global climatology, J. Geophys. Res., 102, $13555-$ $13569,1997$.

Danielsen, E., Hipskind, R. S., Starr, W., Vedder, J., Gaines, S., Kley, D., and Kelly, K.: Irreversible transport in the stratosphere by internal waves of short vertical wavelengths, J. Geophys. Res., 96, 17 433-17 452, 1991.

Dobson, G. M. B.: The laminated structure of the ozone in the atmosphere, Q. J. R. Meteorol. Soc., 99, 599-607, 1973.

Fusco, A. and Salby, M.: Interannual variations of total ozone and their relationship to variations of planetary wave activity, J. Climate, 12, 1619-1629, 1999.

Hood, L., Rossi, S., and Beulen, M.: Trend in lower stratospheric zonal winds, Rossby wave breaking behavior, and column ozone at northern midlatitudes, J. Geophys. Res., 104, D20, $24321-$ 24339, 1999.

James, I. N.: An introduction to circulating atmospheres, Cambridge University Press, 1994.

Mlch, P., and Lavstovivcka, J.: Analysis of laminated structures in ozone vertical profiles in central Europe, Ann. Geophys., 14, 744-752, 1996.

Lemoine, R. and De Backer, H.: Assesment of the Uccle ozone time series quality using SAGE II data, J. Geophys. Res., 106, 14 515-14 523, 2001.

Manney, G. L., Bird, J. C., Donovan, D. P., Duck, T. J., Whiteway, J. A., Pal, S. R., and Carswell, A. I.: Modeling ozone laminae in ground-based Arctic winter time observations using trajectory calculations and satellite data, J. Geophys. Res., 103, 5797-5814, 1998.

McCormick, M. P.: SAGE II: An overview, Adv. Space Res., 7, 3, 219-226, 1987.

O'Connor, F. M., Vaughan, G., and De Backer, H.: Observation of subtropical air in the European mid-latitude lower stratosphere, Q. J. R. Meteorol. Soc., 125, 2965-2986, 1999.

Peters, D. and Waugh, D. W.: Influence of barotropic shear in the poleward advection of upper-tropospheric air, J. Atmos. Sci., 53, 21, 3013-3031, 1996.

Plumb, R. A., Waugh, D. W., Atkinson, R. J., Newman, P. A., Lait, L. R., Schoeberl, M. R., Browell, E. V., Simmons, S. J., and Loewenstein, M.: Intrusions into the lower stratospheric Arctic polar vortex during the winter of 1991/1992, J. Geophys. Res., 94, 11 437-11448, 1994.

Reid, S. J. and Vaughan, G.: Lamination in ozone profiles in the lower stratosphere, Q. J. R. Meteorol. Soc., 117, 825-844, 1991.

Reid, S. J., and Vaughan, G.: Ozone laminae near the edge of the stratospheric polar vortex, J. Geophys. Res., 98, 8883-8890, 1993.

Reid, S. J., Vaughan, G., Mitchell, N. J., Prichard, I. T., Smit, J. H., Jorgensen, T. S., Varotsos, C., and De Backer, H.: Distribution of ozone laminae during EASOE and the possible influence of inertia-gravity waves, J. Geophys. Res., 21, 1479-1482, 1994.

Steinbrecht, W., Claude, H., Köhler, U., and Winkler, P.: Interannual changes of total ozone and northern hemisphere circulation patterns, J. Geophys. Res., 28, 7, 1191-1194, 2001.

Stohl, A.: A 1-year Lagrangian "climatology" of airstreams in the Northern Hemisphere troposphere and lowermost stratosphere, J. Geophys. Res., 106, 7263-7279, 2001. 
Tuck, A. F., Davies, T., Hovde, S. J., Noguer-Alba, M., Fahey, D. W., Kawa, S. R., Kelly, K. K., Murpy, D. M., Proffitt, M. H., Margitan, J. J., Loewenstein, M., Podolske, J. R., Strahan, S. E., and Chan, K. R.: PSC-processed air and potential vorticity in the northern hemisphere lower stratosphere at mid-latitudes during winter, J. Geophys. Res., 97, 7883-7904, 1992.

Varotsos, C., Kalabokas, P., and Chronopoulos, G.: Association of the laminated vertical ozone structure with the lower stratospheric circulation, J. Appl. Meteorol, 33, 473-476, 1994.

Waugh, D. W., Plumb, R. A., Atkinson, R. J., Schoeberl, M. R., Lait, L. R., Newman, P. A., Loewenstein, M., Toohey, D. W., and Webster, C. R.: Transport out of the lower stratospheric Arctic vortex by Rossby Wave breaking, J. Geophys. Res., 99, 10711088, 1994.
World Meteorological Organization (WMO): SAPRC/IOC/GAW Report No. 1, Assessment of trends in the vertical distribution of ozone, Ozone Research and Monitoring Project Report No. 43, 1998.

World Meteorological Organization (WMO): Scientific assessment of Ozone Depletion: 2002, Global Ozone Research and Monitoring Project Report No. 47, 2002. 